\title{
Eskişehir Meralarında Otlatmanın Planlamasında NDVI Verilerinin Kullanılması
}

\author{
${ }^{*}$ Celalettin AYGÜN, A. Levent SEVER, İsmail KARA \\ Illker ERDOĞDU, A. Kadri ATALAY \\ Geçit Kuşağı Tarımsal Araştırma Enstitüsü Müdürlüğü, Eskişehir \\ *Sorumlu yazar e-posta (Corresponding author e-mail): aydadas@gmail.com \\ Geliş Tarihi (Received): 30.03.2016 \\ Kabul Tarihi (Accepted): 29.04.2016
}

\section{Öz}

İl meralarında bitki örtüsünün 10'ar günlük aralıklarla yoğunluğunun dağılımı, vejetasyonun büyümeye başlama, en yüksek yoğunluğa erişme, buna bağlı olarak otlatmaya başlama ve son verme tarihleri gibi mera yönetiminin zamana bağlı olarak değişiminin belirlenmesi amaçlanmıştır. Çalışmada SPOT-Veg NDVI verileri kullanılmıştır. Bu veriler VAST yazılımı ile analiz edilmiş olup buna göre vejetasyon aktivitesi şubat ayının son haftasında (7. periyotta) başlamış, pik noktaya Mayıs ayının birinci ve ikinci haftasında (14. ve 15. periyotlarda) ulaşmıştır. Temmuz ayının son haftasına kadar devam etmiş ve 20. dönemden sonra tedrican azalmaya başlamıştır. Eskişehir ilinde meraların ortalama otlatma gücü 0.81 hektara hayvan otlatma sayısı (HOA) olarak hesaplanmıştır. Buna göre mera vejetasyonunun yıl içerisindeki değişimi izlenerek meraların yönetiminde kullanılabileceği belirlenmiştir.

Anahtar Kelimeler: NDVI, uzaktan algılama, mera, bitki örtüsü, otlatma zamanı

\section{Use of NDVI Data on Planning of Grazing in Eskişehir Grasslands}

\begin{abstract}
The aim of the study is to determine change of grassland management depending on the time, such as distribution of vegetation intensity with 10-days intervals, time of vegetation growth start and reach of highest density and grazing starting and ending dates. SPOT-Veg NDVI data were used in the study. These data were analyzed by VAST software. Accordingly, vegetation activity started in the (period 7) and reached the highest point in the first and second week of May (period 14.15). Vegetation activity continued, but gradually decreased until second week of July (period 20). Average grazing capacity of rangelands in Eskişehir Province was calculated as livestock grazing number per 0.81 hectar. Accordingly, it was concluded that monitoring data of rangeland vegetation during the year can be used in rangeland management.
\end{abstract}

Keywords: NDVI, remote sensing, grassland, vegetation, grazing date

\section{Giriş}

$\mathrm{N}$ DVI (normalize edilmiş bitki indeksi) ile ilgili ilk zamansal kompozit veriler 1980'lerin başlarında kullanılabilir hale gelmiş ve zamanla bu serinin geniş çaplı/çok amaçlı kullanımı ortaya çıkmıştır. Ekolojik çalışmalar yanında meraların uzaktan algılanması çalışmalarında; meraların haritalanması, izlenmesi ve sınıflandırılması ile meralardaki değişimin analizi olarak kabaca üç gurup üzerinde çalışılmış, ikinci gurup çalışmalar bilinen mera alanlarındaki çalışmaların izlenmesi, mera türlerinin analizi, biokütle tahmini, stres algılama, yangın riski gibi geniş bir tematik alan içermiştir. Arazi yüzeyinin ve geniş alanların dinamik değişiminin (bitki örtüsünün) analizi özellikle mevsimsel değişim ve bitki canlılığındaki uzun vadeli değişim ağırlıklı olarak NDVI verileri kullanılarak incelenmiştir. NDVI zaman serisi biomas, tüm üretim öğeleri, bitki fenolojisi, sezonlar arası değişim ve en yaygın olarak mevsimselliği karakterize etmenin yanında mera hayvan ilişkilerinin incelenmesi için kullanılmıştır (Pettorelli et al. 2005; Halabuk 2011; Beck et al. 2008). Belirli bir zaman sürecinde kanopideki klorofil miktarı, bitkinin yeşil olan ve olmayan değişkenlerinin fonksiyonu olarak yorumlanabilir. 


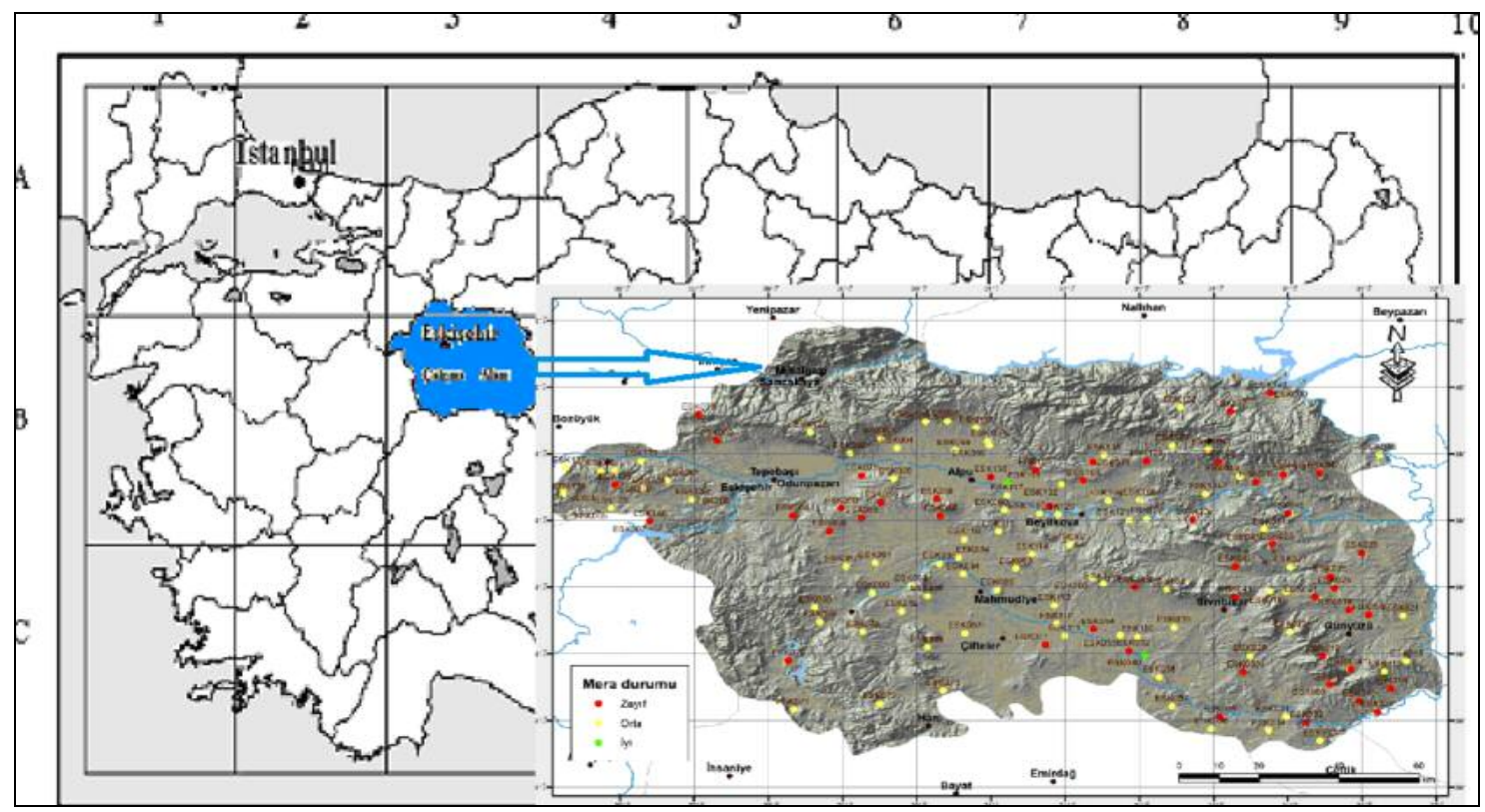

Şekil 1. Eskişehir mera alanları haritası

Figure 1. Map of Eskişehir showing grassland areas

Bitkilerin spektral özellikleri, kendi fenoloji takvimleri içinde değişim göstermektedir. Mera vejetasyonunda da topografyadaki değişime ve iklime bağlı olarak bio-kütlede değişiklikler meydana gelmektedir.

Bitki örtüsü indisleri kullanılarak bitki örtüsü miktarı ve dağılımı belirlenebilir. En yaygın kullanılan bitki örtüsü indislerinden biri normalize edilmiş bitki indeksi (NDVI) olup, yakın kızıl ötesi ve kırmızı bölgede algılama yapmış olan bantlardan faydalanılarak hesaplanır. Oran sonucu piksel değeri parlaksa; sağlıklı bitki örtüsü miktarı daha çoktur. Farklı tarihlerde elde edilen NDVI görüntüleri kullanılarak, bitki örtüsünün mevsimsel değişimleri ortaya konulabilmekte, bitki örtüsü değişimi ile iklim arasındaki ilişki kurulabilmektedir. Kızıl ötesi ve kırmızı bölgede algılama yapan her uydu sisteminden NDVI bilgileri türetilebilmektedir.

Bir bölgedeki meralarda NDVI değerinin yüksek olması o merada bitki yoğunluğunun fazla olduğu ve yine buna bağlı olarak bitki kaplama oranı yüksek erozyon etkisinin az olduğu şeklinde yorumlanabilir. Genel bir kabul olarak yüksek NDVI değerine sahip meraların daha iyi olduğu söylenebilir. Ancak ortamdaki bitki yoğunluğunu oluşturan türlerin mera açısından arzu edilmeyen türlerden de oluşabileceği göz ardı edilmemelidir.

NDVI verileri ile meraların vejetasyon değişiminin izlenmesinde bitkilerin NDVI piksel değeri özellikleri mevsime bağlı olarak değişiklik göstermektedir. Mera yönetimi yanında topografyadaki farklılıklar ve iklim faktörleri de vejetasyonda değişiklikler meydana getirmektedir. Vejetasyonun yeşermesinden sararmasına kadar olan bu değişimler vejetasyon indeksleri yardımıyla tespit edilerek izlenebilmektedir. Bu amaçla uydu görüntülerinden oluşturularak elde edilen normalleştirilmiş vejetasyon indeksi en sık kullanılan yöntemlerden biridir. NDVI arazide bulunan fotosentetik olarak aktif biokütlenin miktarını göstermektedir.

Dünya'da otlatılarak değerlendirilen gerçek doğal meralar yaklaşık 3.357 milyar ha. alan ile dünya kara alanlarının \%26'sına karşılık gelmektedir. Mera alanları ülkemizde 14.616.687 ha. Orta Anadolu bölgesinde ise 4.902.000 ha. ile geniş bir yer kaplamaktadır (Altın ve ark. 2011).

Eskişehir mera alanları, Orta Anadolu ve Marmara bölgeleri arasında batı geçit bölgesinde kurak ve yarı kurak mera ekosistemi özelliğindedir.

Eskişehir İlinin toplam yüzölçümü 1.347.971 ha. olup, bunun 581.610 ha'lık (\%43.1) kısmı işlenen tarım arazisi 337.178 ha'ık (\%25.0) kısmı ormanlık ve fundalık alan, 320.966 ha.'lık (\%23.8) alan ise mera alanı olarak 22.914 ha. (\%1.7) daimi çayır ve 


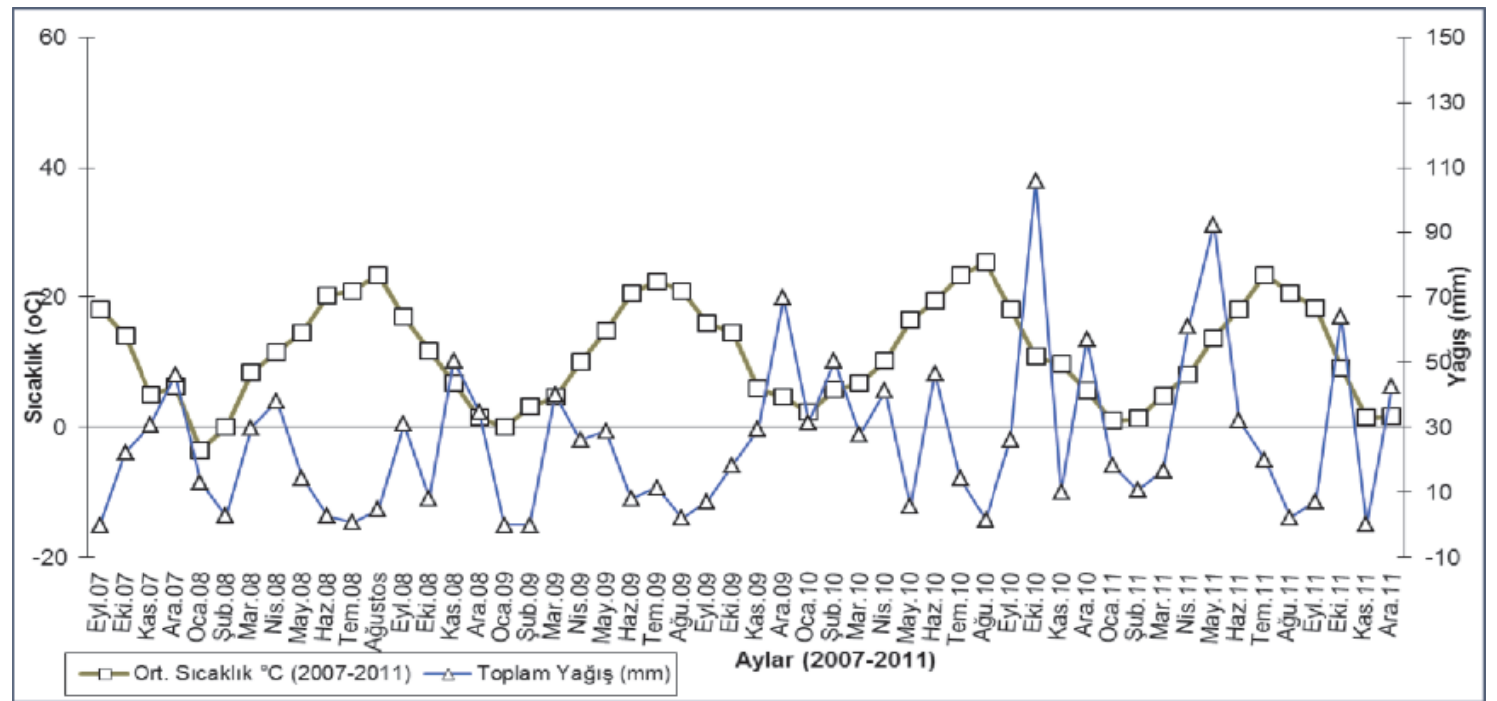

Şekil 2. Eskişehir 2007-2011 yılları arası iklim değerleri

Figure 2. Long-term meteorogical data of 2007-2011 years in Eskişehir

tarıma elverişiz arazi (taşlık, bataklık, çorak vb. arazi) 289.722 ha. (\%21.5) şeklinde dağılım göstermektedir (Anonim 2016). Eskişehir ili, Davis, (1965)'in Türkiye kareleme sistemine göre A3 ve B3 kareleri içerisinde İran-Turan flora bölgesinde yer almakta olup (Şekil 1), çalışma alanı meraların yüksekliği 515-1319 m. arasında değişmekle birlikte ortalama 946.8 m'dir (Aygün ve ark. 2013). Uzun yıllar ortalama yağış $347.1 \mathrm{~mm}$. ve uzun yıllar ortalama sıcaklıklar ise $13.7^{\circ} \mathrm{C}$ olup, 2007-2011 yılları arası aylık ortalama sıcaklık ve aylık toplam yağış değerleri Şekil 2'de verilmiştir (Anonim 2011).

Bitki örtme oranları ile NDVI değerleri arasında ve kızıl ötesi ışın kullanımları arasında da yüksek regresyon saptanmıştır (Genç ve ark. 2008). NDVI endeksleri ile farklı bitki rotasyonları, sulama sistemleri ve gübre uygulamaları için algoritmalar geliştirilebileceği ve bu tür uygulamalar için kullanılabileceği bildirilmiştir (Yin et al. 2010). Optik algılamalar bitkilerin ihtiyacı olan gübre uygulamaları için hassas ölçüm yöntemlerinden olup, maliyeti en aza indiren bir araç olarak değerlendirilmiştir (Raun et al. 2001; Raun et al. 2002; Teal et al. 2006; Tubana et al. 2008). Bu değişik çözünürlükteki teknoloji ile gübre uygulamalarının da aynı hassasiyette kullanılabileceği bildirilmiştir. Bu uygulamaların daha çok tarla bitkileri üzerine yoğunlaşarak verimlerde \%15'lere varan artışlar sağladığı belirtilmiştir (Raun et al. 2002).

Uzaktan algılama verileri ile bitki klorofil içeriğinin tahmin edilmesi amacıyla kullanılan yöntemler, yakın kızıl ötesi ve kırmızı ışık bandında algılanan uydu verilerine dayanmaktadır. NDVI temel olarak, sağlıklı bitki örtüsünden yansıyan radyasyonun, diğer tüm kaynaklardan yansıyan radyasyona oranıdır.

Tarımın yoğun olduğu bölgeler gözlendiğinde, düşük NDVI değerlerine sahip alanlar kuraklık, aşırı rutubet, hastalık ve zararlılar gibi çeşitli nedenlerle zayıf bitki gelişiminin olduğu alanları işaret etmektedir. Yüksek NDVI değerleri ise sağlıklı bitki gelişiminin olduğu alanları göstermektedir.

Çevresel ve doğal kaynakların yönetimi, küresel ve bölgesel arazi örtüsü/kullanımı değişimlerinin belirlenmesi gibi bir çok uygulama yanında global olarak hazırlanmış olan arazi örtüsü verileri kullanılmaktadır (Sertel 2008; Pitman 2003; Sellers et al. 1996; Skole and Tucker 1993; Sertel ve Örmeci. 2009; Loveland et al. 2000).

\section{Materyal ve Yöntem}

NDVI= (IR-RED)/(IR+RED) formülünde belirtildiği gibi bu iki dalga boyunun matematiksel modellemesi ile oluşturulan vejetasyon indeksi (NDVI) bitkilerin canlı biokütle miktarı ve yaprak alan indeks değerinin ana göstergesi olarak kabul edilir ve yetişme döneminde bitki gelişiminin izlenmesi 
ve verim tahmini amacıyla kullanılır. NDVI indeks değerleri teorik olarak $(-1)$ ile $(+1)$ arasında değişir. Yeşil bitki örtüsünün fazla olduğu alanlarda indeks değeri +1 'e doğru yaklaşırken, bulutlar, su ve kar düşük (eksi) NDVI indeks değerlerine neden olur. Çıplak toprak ve zayıf vejetasyon ise sıfıra yakın NDVI değeri gösterir.

Mera vejetasyonunun yıl içersinde gelişimini izlediğimizde kışın indeks değerleri 0 ve -1'e yakın iken ilkbaharda bitki örtüsünün canlanması ile indeks değerleri artmakta ve daha sonra yaz kuraklığı ile tekrar azalarak çan eğrisine benzer bir değişim göstermektedir. SPOT-VEG verileri $1 \mathrm{~km}$ 'lik mekânsal çözünürlüğe sahip olduklarından hem küresel hem de bölgesel çalışmalarda sıklıkla kullanılabilmektedir.

$\mathrm{Bu}$ çalışmada Dünya Gıda Örgütünün (FAO), vejetatif gelişimin izlenmesi amacıyla yürüttüğü ARTEMIS projesi kapsamında kullandığı SPOT-VEG uydu görüntülerinden üretilmiş 10'ar günlük maksimum vejetasyon indeks (NDVI) verileri kullanılmıştır.

1999-2009 yıllarına ait 10 yıllık, 10'ar günlük SPOT-VEG $\left(1 \mathrm{~km}^{2}\right)$ uydu görüntülerinden elde edilen NDVI görüntüleri bu analiz için kullanılmıştır. Bu görüntüler her yıl için 36 adet olup yılın her on günlük dilimini temsil etmektedir. 10 yıllık görüntüler kullanılarak her bir on günlük dönemler için bir ortalama görüntü üretilmiştir. 10 yılı temsil eden bu görüntüler üzerine gidilen mera duraklarına ait koordinatlar bindirilerek her bir mera noktasının görüntüdeki NDVI piksel değeri alınmış ve mera ziyaretlerinden elde edilen koordinat verileri kullanılarak farklı bölgeler için mera vejetasyonunun takibi yapılmıştır. Daha sonra bu noktaları temsil eden NDVI değerlerinin aritmetik ortalaması alınıp grafikler ve tablolar üretilmiştir. NDVI grafikleri yardımıyla mera durum ve kalitesi yorumlanmış, ayrıca otlatma yönetimi de belirlenmeye çalışılmıştır. Uzaktan algılanmış veriler kullanılarak yeryüzü özellikleri hakkında hızlı, ekonomik ve güncel bilgiler üretilebilmekte, uydu sistemleri ile gerek geçmişin gerekse mevcut durumun analizine yönelik olarak çok zamanlı veri elde edebilme imkânı sağlanmaktadır (Sertel ve Örmeci 2009; Saroğlu 2004).

\section{Bulgular ve Tartışma}

Otlatma yönetiminin NDVI grafikleri ile meralara göre değerlendirilmesinde Eskişehir genel, iyi, orta ve zayıf meraları için 10'ar günlük dönemler halinde NDVI indeks değerleri hesaplanmış olup, açık yeşilden koyu yeşile doğru renkler vejetasyon canlılığında normale göre artış olduğunu göstermektedir.

Belirli bir zaman sürecinde kanopideki klorofil miktarı, bitkinin yeşil olan ve olmayan değişkenlerinin fonksiyonu olarak yorumlanabilir. Bitkilerin spektral özellikleri, kendi fenoloji takvimleri içinde değişim göstermektedir. Mera vejetasyonunda da topografyadaki değişime ve iklime bağlı olarak biokütlede değişiklikler meydana

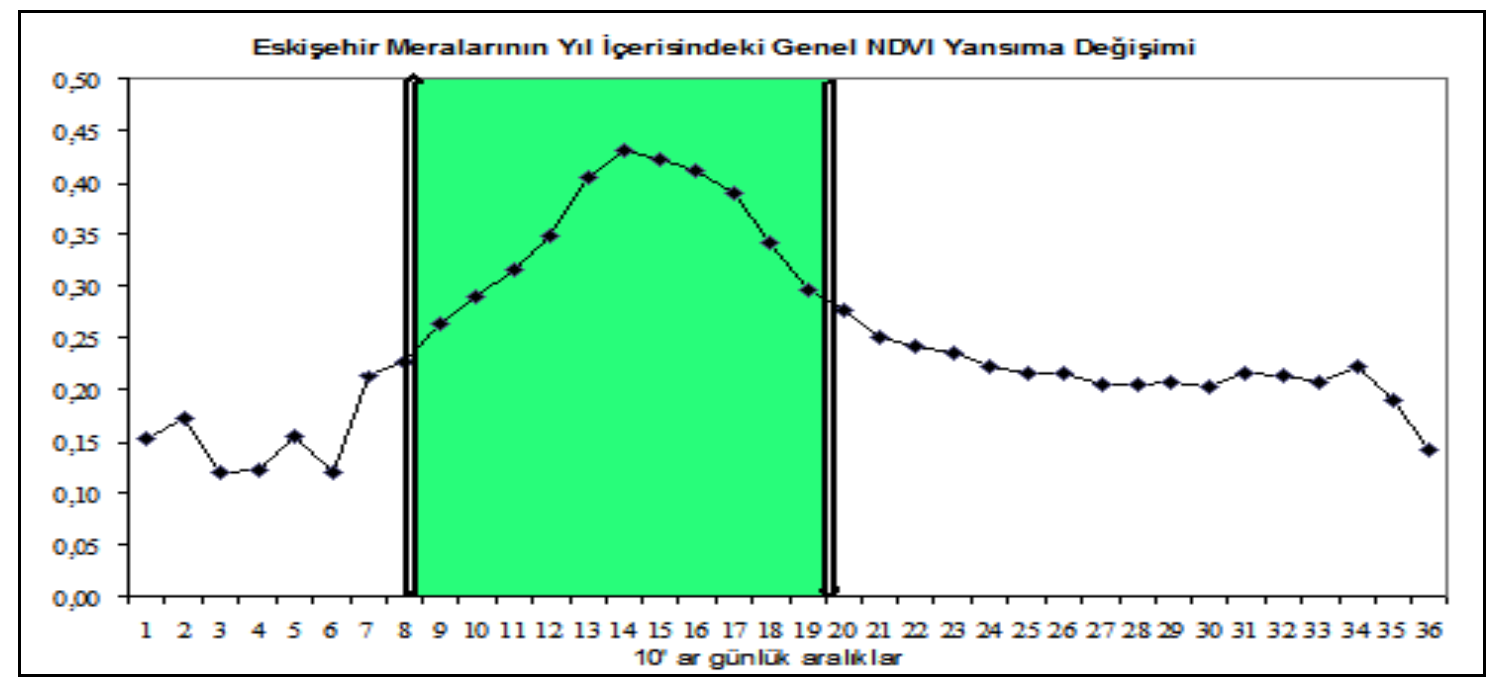

Şekil 3. Eskişehir meralarının yıl içerisindeki 10'ar günlük NDVI piksel değeri değişimi

Figure 3. Ten-day- pixel values reflection changes on NDVI in Eskisehir grasslands 
gelmektedir. Ülkemizin çok farklı topoğrafik ve iklimsel değişkenliğe sahip olması mera vejetasyonu takviminde (vejetasyon başlangıcı, en yüksek seviye vb.) farklııklar oluşturmaktadır.

NDVI zaman serisi grafiklerinden faydalanılarak mera vejetasyonundaki mevsimsel döngü zamana bağlı olarak izlenebilir. Bir bölgedeki meralarda otlatmaya başlama ve otlatmaya son verme tarihlerine karar verirken NDVI bilgisinden yardımcı veri olarak faydalanılabilir (Koç ve Gökkuş 1999; Terzioğlu ve Yalvaç 2004). Ekili alanlarda bitki gelişimini takip etmek için uydu verileri kullanılmaktadır (Karayusufoğlu ve ark. 2011).

Eskişehir meralarının geneline bakıldığında; beklendiği gibi kış aylarında özellikle Aralık, Ocak ve Şubat aylarında NDVI değerleri en düşük olmuştur. Bunun nedeni; 2010 yılı dışında toplam yağış ve sıcaklıklar düşük olduğundan kış aylarında vejetasyonun uyku döneminde olması arazide çıplak toprak, taş ve kar örtüsünün hâkim olmasıdır. İndeks değerlerinin genellikle 7. on günlük dönemde yani Şubat sonu Mart ayının birinci haftasında yükselmeye başladığı görülmektedir. Bu dönemlerde hem sıcaklık hemde yağış nispeten artmaktadır. Bu durum meralarda ilkbahar dönemi vejetasyon aktivitesinin başladığını göstermektedir (Şekil $3)$.

NDVI indeks değerleri 14. ve 15. dönemde yani Mayıs ayının başından itibaren en yüksek değerlere ulaşmış olup, bu değerler Temmuz ayının son haftasına kadar devam etmiş ve 20. dönemden sonra nispeten azalmaya başlamıştır. İlkbahar yağışlarını alan mera alanları sıcaklığın yükselmesiyle bereber vejetasyonda artış başlamıştır. NDVI grafiklerine baktığımızda meralara göre değişmekle birlikte en yüksek NDVI piksel değeri 14. ve 15. Dönem (Mayıs ayı ortaları) erişilmekte olup otlatma başlangıç tarihleri olarak 9. ve 10. Dönem (Mart ayı sonu, Nisan ayı başı) alınabilir. Durumun genel değerlendirilmesinde; Eskişehir meralarının yüksek NDVI değeri gösterdiği belirlenmiştir(Tablo 1).

İyi meralar için oluşan NDVI değerleri 0.13-0.42 arasında değişmiş (Tablo 2), Redis mera durum sınıfına göre Eskişehirde 15 adet iyi meranın vejetasyonun gelişmesi Mart ayı başı, yani 7. dönemde gelişmeye başlamış olup (0.21) bu dönem vejetasyonun yarısına ulaşıldığı dönem olmaktadır. Bu dönemde toplam aylık yağışla birlikte sıcaklıkta artmakta dolayısıyla vejetasyon uyanmaktadır (Şekil 4).

Otlatma olgunluğuna Mart ayı sonu, Nisan ayı başına 9. 10. ve 11. dönemlerde ulaşmakta olup, Nisan ayındaki sıcaklık ve yağış ortalamanın üzerinde seyretmektedir. 2010 yılı dışında Mayıs ayı yağışı uzun yıllar ortalamalarında olup sıcaklıkta sürekli yükselme eğilimi göstermektedir. Mayıs ayı ortalarında 14. dönemde en yüksek (0.42) seviyesine ulaşmaktadır. Nisan ayının son haftasından (12. dönem), Haziran ayının ikinci haftası (17. dönem) arasında yükselmekte ve Haziran ayının son haftasından(18 dönem) Ağustos ayının ikinci haftasına (23. dönem) kadar çok fazla değişmeden kalmaktadır. Bu dönemlerde

Çizelge 1. Eskişehir meralarının 10 günlük dönemsel NDVI piksel değeri değişimi

Table 1. Ten-day- pixel values changes on NDVI in Eskisehir grasslands

\begin{tabular}{|c|c|c|}
\hline Aylar & Haftalar & Genel Mera \\
& 1 & 0.13 \\
Ocak & 2 & 0.16 \\
& 3 & 0.11 \\
Şubat & 4 & 0.13 \\
& 5 & 0.15 \\
Mart & 6 & 0.12 \\
& 7 & 0.20 \\
Nisan & 8 & 0.21 \\
& 10 & 0.25 \\
Mayıs & 11 & 0.28 \\
& 12 & 0.30 \\
Haziran & 13 & 0.34 \\
& 15 & 0.38 \\
Temmuz & 16 & 0.41 \\
& 17 & 0.40 \\
Ağustos & 19 & 0.38 \\
& 20 & 0.31 \\
Eylül & 21 & 0.26 \\
& 23 & 0.23 \\
& 24 & 0.22 \\
Ekim & 25 & 0.22 \\
& 27 & 0.20 \\
Kasım & 28 & 0.20 \\
& 29 & 0.19 \\
Aralık & 30 & 0.19 \\
& 31 & 0.19 \\
& 32 & 0.20 \\
& 33 & 0.20 \\
& 35 & 0.19 \\
& 36 & 0.20 \\
& & 0.14 \\
\hline
\end{tabular}




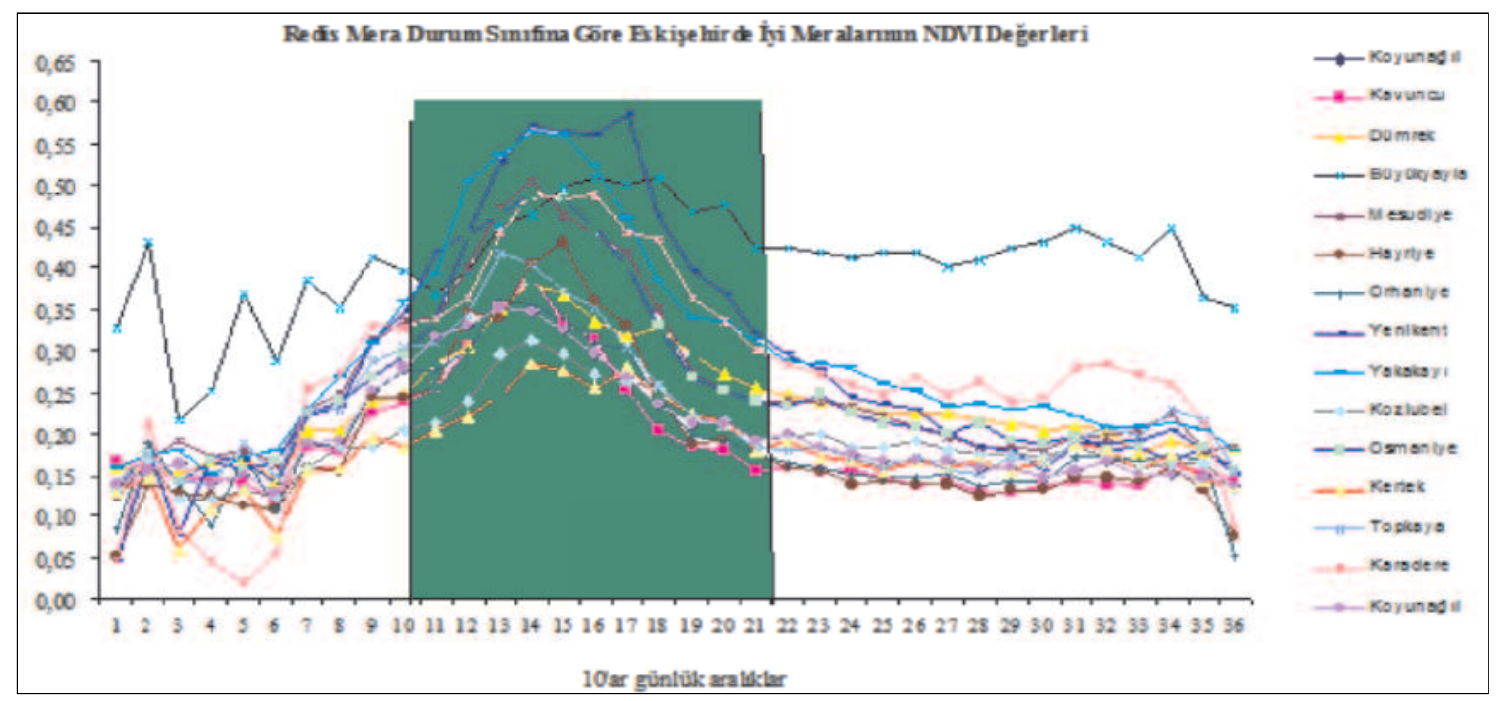

Şekil 4. Eskişehirde iyi mera durumu sınıfına ait meraların NDVI verileri

Figure 4. NDVI data of Eskisehir grasslands occupyng good conditions

ise yüksek sıcaklık ve düşük yağış vejetasyonu durağan kılmıştır. Ağustos ayı sonu, 24. dönemden itibaren ise hızla düşmeye başlamış (0.21), 2008 yılı Ekim ayı dışında alınan yağışlar nedeniyle 28. 29. ve 30. dönemde tekrar otlatma olgunluğuna ulaşarak bir aylık dönemde otlatmaya elverişli duruma ulaşmıştır.

Orta sınıf meralarda NDVI değerleri 0.100.40 arasında değişmiş (Tablo 3) Redis mera durum sınıfına göre 47 adet orta sınıf meralarda (Şekil 5) vejetasyonun gelişmesi Mart ayı başında $(0.21)$ toplam vejetasyonun yarısına ulaştığı dönemde (7. dönem) başlamış ve otlatma olgunluğuna ise Mart ayı sonu (0.26) (9. dönem) de ulaşılmıştır.

Nisan ayının sonu itibariyle yükselmeye başlayan vejetasyon Haziran ayının 17. dönemine kadar yükselmeye devam etmiştir. 2007-2011 yıllarında Nisan ayındaki sıcaklık ve yağış ortalamanın üzerinde seyretmekte olup, 2010 yılı dışında Mayıs ayı yağışı uzun yıllar ortalamalarında olup, sıcaklık sürekli yükselme eğilimi göstermiştir. Vejetasyon en yüksek noktaya ise Mayıs ayı ortasında (0.43), 14. dönem de ulaşmıştır. Haziran ayının son haftasından (18. dönem), Ağustos ayını ikinci haftasına kadar sabit kalmıştır. Bu dönemlerde ise yüksek sıcaklık ve düşük yağış vejetasyonun gelişmesini engellemiştir.

Ağustos ayı sonu (24. dönem) hızla düşmeye başlayan vejetasyon tekrar sezon başına kadar gelişme göstermemiştir.

Eskişehir'de Redis mera durum sınıfına göre çalışılan 80 adet zayıf merada (Şekil 6) NDVI
Çizelge 2. Eskişehir iyi meralarının 10 günlük dönemsel NDVI piksel değeri

Table 2. Figure 10. Ten-day- pixel values changes on NDVI in Eskisehir grasslands occupying good conditions

\begin{tabular}{|c|c|c|}
\hline Aytar & $\begin{array}{c}\text { Haftalar } \\
1\end{array}$ & $\begin{array}{c}\text { Eskişe hir } \\
0.13\end{array}$ \\
\hline \multirow[t]{2}{*}{ Ocak } & $\frac{2}{3}$ & $\begin{array}{l}0.19 \\
0.14\end{array}$ \\
\hline & 4 & 0.14 \\
\hline \multirow[t]{3}{*}{ Şubat } & 5 & 0.16 \\
\hline & 6 & 0.14 \\
\hline & 7 & 0.21 \\
\hline \multirow[t]{3}{*}{ Mart } & 8 & 0.22 \\
\hline & 9 & 0.27 \\
\hline & 10 & 0.29 \\
\hline \multirow[t]{3}{*}{ Nisan } & 11 & 0.31 \\
\hline & 12 & 0.35 \\
\hline & 13 & 0.40 \\
\hline \multirow[t]{3}{*}{ Mayns } & 14 & 0.42 \\
\hline & 15 & 0.41 \\
\hline & 16 & 0.38 \\
\hline \multirow[t]{3}{*}{ Haziran } & 17 & 0.36 \\
\hline & 18 & 0.32 \\
\hline & 19 & 0.27 \\
\hline \multirow[t]{3}{*}{ Ternmuz } & 20 & 0.26 \\
\hline & 21 & 0.24 \\
\hline & 22 & 0.23 \\
\hline \multirow[t]{3}{*}{ Ağustos } & 23 & 0.23 \\
\hline & 24 & 0.21 \\
\hline & 25 & 0.21 \\
\hline \multirow[t]{3}{*}{ Eyłù1 } & 26 & 0.21 \\
\hline & 27 & 0.20 \\
\hline & 28 & 0.30 \\
\hline \multirow[t]{3}{*}{ Ekcim } & 29 & 0.29 \\
\hline & 30 & 0.27 \\
\hline & 31 & 0.21 \\
\hline \multirow[t]{3}{*}{ Kastm } & 32 & 0.20 \\
\hline & 33 & 0.19 \\
\hline & 34 & 0.21 \\
\hline \multirow[t]{2}{*}{ Aralnk } & 35 & 0.19 \\
\hline & 36 & 0.15 \\
\hline
\end{tabular}




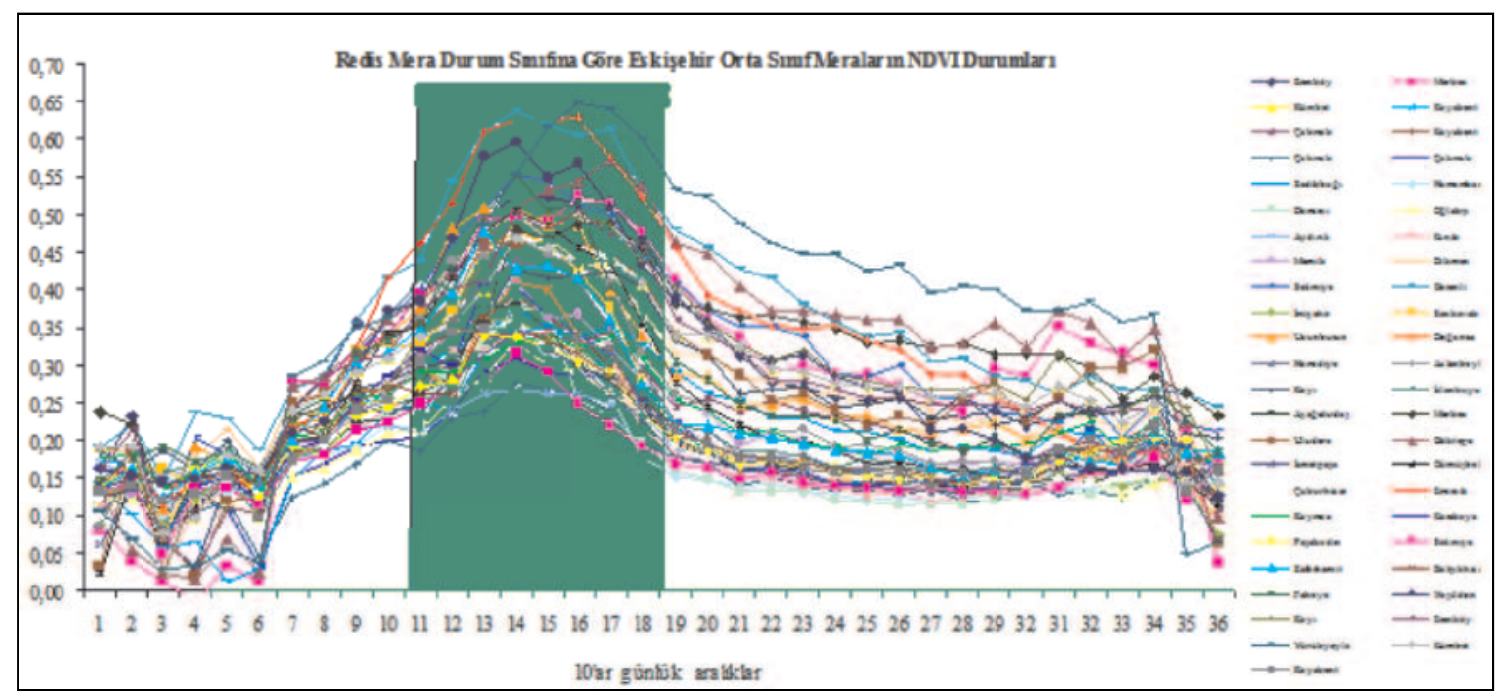

Şekil 5. Eskişehirde orta mera durumu sınıfına ait meraların NDVI verileri

Figure 5. NDVI data of Eskisehir grasslands occupyng moderate conditions

Çizelge 3. Eskişehir orta meralarının 10 günlük dönemsel NDVI piksel değeri

Table 3. Figure 10. Ten-day- pixel values changes on NDVI in Eskisehir grasslands occupying moderate conditions

\begin{tabular}{|c|c|c|}
\hline \multirow[t]{2}{*}{ Ayar } & Faftalar & Eskişehir \\
\hline & 1 & 0.14 \\
\hline \multirow[t]{3}{*}{ Ocak } & 2 & 0.16 \\
\hline & 3 & 0.1 \\
\hline & 4 & 0.13 \\
\hline \multirow[t]{3}{*}{ Subat } & 5 & 0.14 \\
\hline & 6 & 0.12 \\
\hline & 7 & 0.21 \\
\hline \multirow[t]{3}{*}{ Nart } & 8 & 0.22 \\
\hline & 9 & 0.26 \\
\hline & 10 & 0.29 \\
\hline \multirow[t]{3}{*}{$\mathrm{N}_{1} \operatorname{san}$} & 11 & 0.31 \\
\hline & 12 & 0.35 \\
\hline & 13 & 0.40 \\
\hline \multirow[t]{3}{*}{ Mayns } & 14 & 0.43 \\
\hline & 15 & 0.40 \\
\hline & 16 & 0.40 \\
\hline \multirow[t]{3}{*}{ Haziran } & 17 & 0.38 \\
\hline & 18 & 0.33 \\
\hline & 19 & 0.28 \\
\hline \multirow[t]{3}{*}{ Termmuz } & 20 & 0.26 \\
\hline & 21 & 0.24 \\
\hline & 22 & 0.23 \\
\hline \multirow[t]{3}{*}{ A.ğustos } & 23 & 0.22 \\
\hline & 24 & 0.21 \\
\hline & 25 & 0.21 \\
\hline \multirow[t]{3}{*}{ EyAü1 } & 26 & 0.21 \\
\hline & 27 & 0.19 \\
\hline & 28 & 0.19 \\
\hline \multirow[t]{3}{*}{ Elcim } & 29 & 0.19 \\
\hline & 30 & 0.19 \\
\hline & 31 & 0.21 \\
\hline \multirow[t]{3}{*}{ Kasim } & 32 & 0.21 \\
\hline & 33 & 0.20 \\
\hline & 34 & 0.22 \\
\hline \multirow[t]{2}{*}{ Aralik } & 35 & 0.17 \\
\hline & 36 & 0.14 \\
\hline
\end{tabular}

Çizelge 4. Eskişehir orta meralarının 10 günlük dönemsel NDVI piksel değeri

Table 4. Figure 10. Ten-day- pixel values changes on NDVI in Eskisehir grasslands occupying moderate conditions

\begin{tabular}{|c|c|c|}
\hline \multirow[t]{2}{*}{ Aylar } & Ha ftalar & Eskişehir \\
\hline & 1 & 0.12 \\
\hline \multirow[t]{2}{*}{ Ocak } & $\frac{2}{3}$ & $\begin{array}{l}0.16 \\
0.11\end{array}$ \\
\hline & 4 & 0.13 \\
\hline \multirow[t]{3}{*}{ Subat } & 5 & 0.16 \\
\hline & 6 & 0.12 \\
\hline & 7 & 0.20 \\
\hline \multirow[t]{3}{*}{ Mart } & 8 & 0.21 \\
\hline & 9 & 0.25 \\
\hline & 10 & 0.27 \\
\hline \multirow[t]{3}{*}{ Nisan } & 11 & 0.29 \\
\hline & 12 & 0.33 \\
\hline & 13 & 0.37 \\
\hline \multirow[t]{3}{*}{ Mayns } & 14 & 0.40 \\
\hline & 15 & 0.38 \\
\hline & 16 & 0.37 \\
\hline \multirow[t]{3}{*}{ Haziran } & 17 & 0.34 \\
\hline & 18 & 0.30 \\
\hline & 19 & 0.25 \\
\hline \multirow[t]{3}{*}{ Temmuz } & 20 & 0.24 \\
\hline & 21 & 0.24 \\
\hline & 22 & 0.21 \\
\hline \multirow{3}{*}{ Ağustos } & 23 & 0.21 \\
\hline & 24 & 0.20 \\
\hline & 25 & 0.19 \\
\hline \multirow[t]{3}{*}{ Eyiü1 } & 26 & 0.19 \\
\hline & 27 & 0.18 \\
\hline & 28 & 0.18 \\
\hline \multirow[t]{3}{*}{ Ekim } & 29 & 0.18 \\
\hline & 30 & 0.18 \\
\hline & 31 & 0.19 \\
\hline \multirow[t]{3}{*}{ Kasim } & 32 & 0.19 \\
\hline & 33 & 0.18 \\
\hline & 34 & 0.20 \\
\hline \multirow[t]{2}{*}{ Aralnk } & 35 & 0.17 \\
\hline & 36 & 0.14 \\
\hline
\end{tabular}

NDVI: Normalize edilmiş bitki indeksi

NDVI: Normalized Difference Vegetation Index 


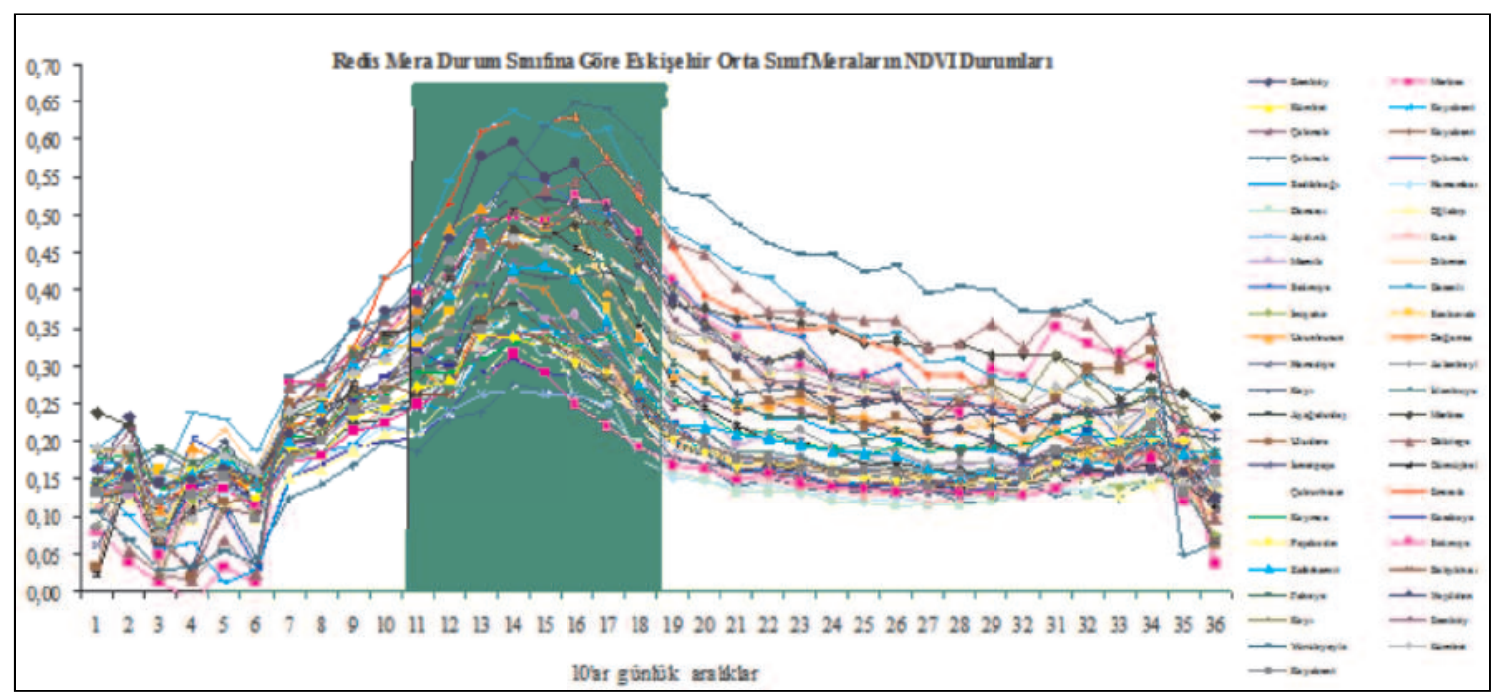

Şekil 6. Eskişehirde zayıf mera durumu sınıfına ait meraların NDVI verileri

Figure 6. NDVI data of Eskisehir grasslands occupyng poor conditions

Çizelge 5. Eskişehir meralarının 10'ar günlük dönemsel NDVI piksel değeri değişimi Table 5. Ten-day- pixel values changes on NDVI in Eskisehir grasslands

\begin{tabular}{|c|c|c|c|c|c|c|}
\hline \multirow[b]{2}{*}{ Aylar } & \multirow{2}{*}{ Haftalar } & & \multicolumn{4}{|c|}{ Eskişehir İli Meralarının NDVI Piksel Değeri Değişimleri } \\
\hline & & & Genel Mera & İyi Mera & Orta Mera & Zayıf Mera \\
\hline \multirow{3}{*}{ Ocak } & 1 & \multirow{6}{*}{ 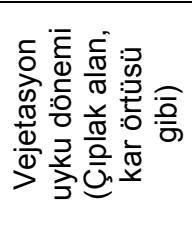 } & 0.13 & 0.13 & 0.14 & 0.12 \\
\hline & 2 & & 0.16 & 0.19 & 0.16 & 0.16 \\
\hline & 3 & & 0.11 & 0.14 & 0.10 & 0.11 \\
\hline \multirow{3}{*}{ Şubat } & 4 & & 0.13 & 0.14 & 0.13 & 0.13 \\
\hline & 5 & & 0.15 & 0.16 & 0.14 & 0.16 \\
\hline & 6 & & 0.12 & 0.14 & 0.12 & 0.12 \\
\hline \multirow{3}{*}{ Mart } & 7 & & 0.20 & 0.21 & 0.21 & 0.20 \\
\hline & 8 & & 0.21 & 0.22 & 0.22 & 0.21 \\
\hline & 9 & & 0.25 & 0.27 & 0.26 & 0.25 \\
\hline & 10 & & 0.28 & 0.29 & 0.29 & 0.27 \\
\hline \multirow[t]{3}{*}{ Nisan } & 11 & & 0.30 & 0.31 & 0.31 & 0.29 \\
\hline & 12 & $\Phi$ & 0.34 & 0.35 & 0.35 & 0.33 \\
\hline & 13 & $\sum$ & 0.38 & 0.40 & 0.40 & 0.37 \\
\hline \multirow[t]{3}{*}{ Mayıs } & 14 & $\frac{\grave{c}}{\sigma}$ & 0.41 & 0.42 & 0.43 & 0.40 \\
\hline & 15 & ᄃ & 0.40 & 0.41 & 0.40 & 0.38 \\
\hline & 16 & ते & 0.38 & 0.38 & 0.4 & 0.37 \\
\hline \multirow[t]{3}{*}{ Haziran } & 17 & $\pi$ & 0.35 & 0.36 & 0.38 & 0.34 \\
\hline & 18 & $\frac{\omega}{\omega}$ & 0.31 & 0.32 & 0.33 & 0.30 \\
\hline & 19 & $>$ & 0.26 & 0.27 & 0.28 & 0.25 \\
\hline \multirow[t]{3}{*}{ Temmuz } & 20 & & 0.25 & 0.26 & 0.26 & 0.24 \\
\hline & 21 & & 0.23 & 0.24 & 0.24 & 0.24 \\
\hline & 22 & & 0.22 & 0.23 & 0.23 & 0.21 \\
\hline \multirow[t]{3}{*}{ Ağustos } & 23 & & 0.22 & 0.23 & 0.22 & 0.21 \\
\hline & 24 & & 0.20 & 0.21 & 0.21 & 0.20 \\
\hline & 25 & 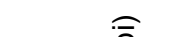 & 0.20 & 0.21 & 0.21 & 0.19 \\
\hline \multirow[t]{3}{*}{ Eylül } & 26 & $\bar{\varepsilon}$ & 0.20 & 0.21 & 0.21 & 0.19 \\
\hline & 27 & 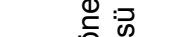 & 0.19 & 0.20 & 0.19 & 0.18 \\
\hline & 28 & : : & 0.19 & 0.19 & 0.19 & 0.18 \\
\hline \multirow[t]{3}{*}{ Ekim } & 29 & 론:은 & 0.19 & 0.19 & 0.19 & 0.18 \\
\hline & 30 & 方武 & 0.18 & 0.19 & 0.19 & 0.18 \\
\hline & 31 & ป็ & 0.20 & 0.21 & 0.21 & 0.19 \\
\hline \multirow[t]{3}{*}{ Kasım } & 32 & $\widehat{d} \frac{\sqrt{0}}{\pi}$ & 0.20 & 0.20 & 0.21 & 0.19 \\
\hline & 33 & 苛递 & 0.19 & 0.19 & 0.20 & 0.18 \\
\hline & 34 & $\stackrel{0}{\infty}$ & 0.20 & 0.21 & 0.22 & 0.2 \\
\hline \multirow[t]{2}{*}{ Aralık } & 35 & Q & 0.17 & 0.19 & 0.17 & 0.17 \\
\hline & 36 & & 0.14 & 0.15 & 0.14 & 0.14 \\
\hline
\end{tabular}




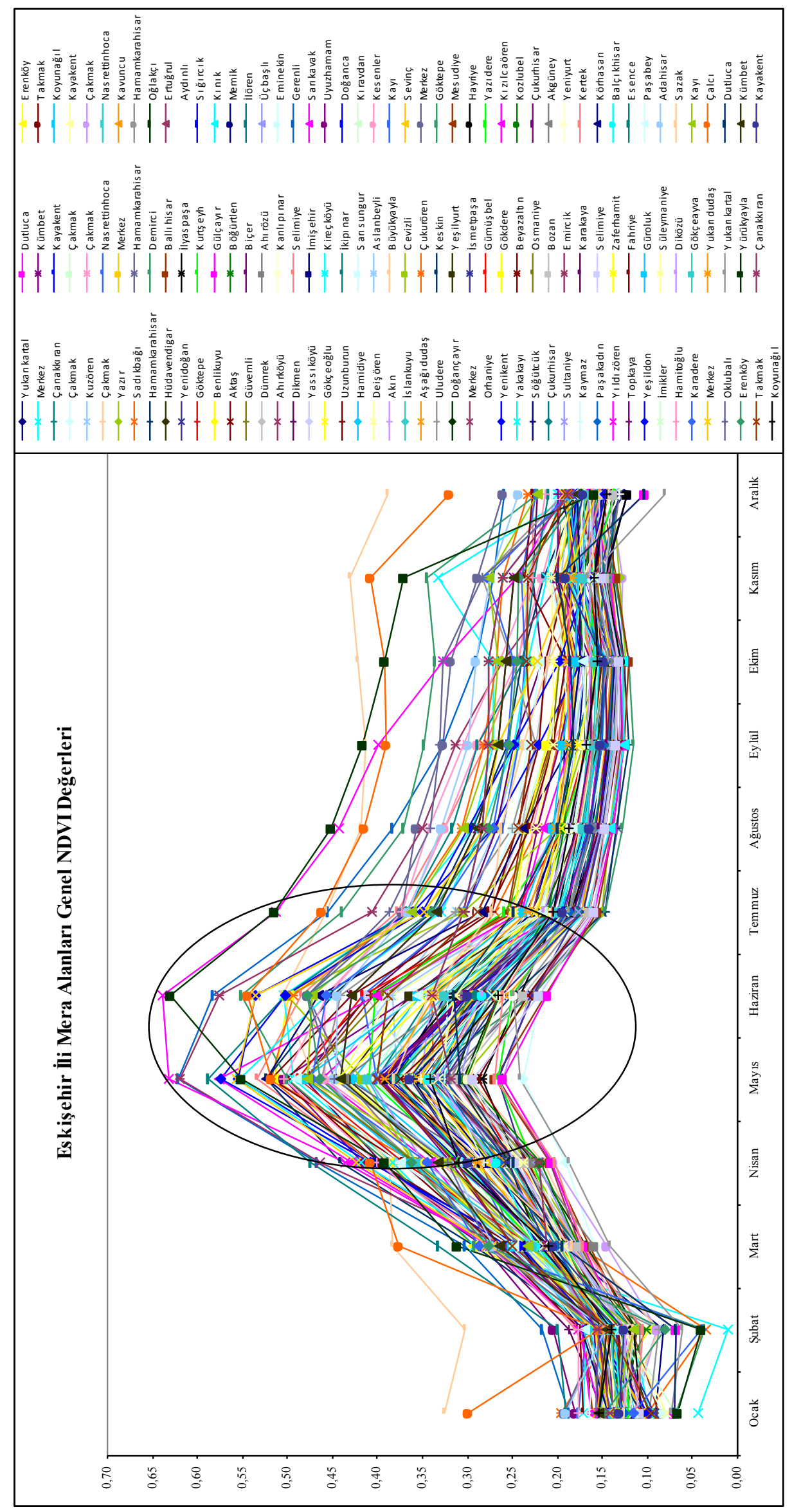

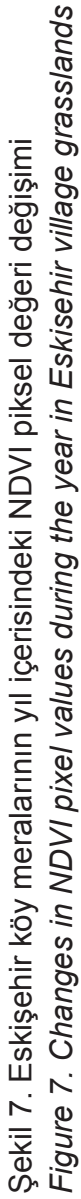


değerleri 0.11-0.40 arasında değişmiş (Tablo 4). Vejetasyonun gelişmesi Mart ayı başlarında (0.20), (7. dönem) iyi ve orta meralara göre daha geç başlamış ve Nisan ayının ikinci haftasına (11. dönem) kadar sabit kalmış olup yağış Mart ayında düşük ve Nisan ayında artmaya başlamış, sıcaklıkla birlikte vejetasyon Nisan ayının son haftasından (12. dönem) Haziran ayının ikinci haftasına kadar hızlıca gelişmeye devam etmiş, Mayıs ayının ikinci haftasında 14. dönemde en yüksek seviyeye ulaşmıştır.

Vejetasyonda azalma Temmuz ayının ilk haftasından (19. dönem) itibaren Ağustos ayının ikinci haftası da dahil (23. dönem) sabit kalmış, yaz döneminde hatta Eylül ayında da yağış düşük sıcaklık ise en yüksek derecede olup, 24. dönemden itibaren hızla azalmaya başlamış ve tekrar sezon sonuna kadar otlatmaya imkan tanımamıştır.

Genel olarak ise; Tablo 5'de görüldüğü üzere vejetasyonun uyku dönemi Ocak ayının birinci döneminden Şubat ayının üçüncü yani 6 . döneme kadar devam etmekte olup, bu dönemde meralar otlatma için yeterli ve uygun değildir. Otlatmaya başlama zamanı Mart ayının birinci haftasından yani 7 . dönemden başlamaktadır. Mera durum sınıflarına göre en yüksek noktaya 14 ve 15 dönemlerde ulaşmakta, Ağustos ayının ortlarından itibaren(23 dönem) ise otlatma dönemi sona ermektedir. 24. dönemden itibaren bitkilerde yağışa bağlı olarak nispi bir büyüme olsa bile bu durum otlatma için yeterli değildir.

\section{Sonuç}

NDVI grafiklerinden otlatmanın planlanması amacıyla kullanılması gerektiğinde; toplam NDVI piksel değerinin yarısına ulaşıldığı yer otlatmaya başlama tarihi, sonbaharda NDVI piksel değeri hızla azalmaya başladığı noktanın 3-4 hafta öncesi de son verme tarihi olarak değerlendirilebilir. Yine meralarda gerek verim ve buna bağlı olarak otlatma süresinin uzatılmasında etkili yöntemlerden olan gübreleme çalışmalarında farklı sezonlardaki bitki boyları ve canopy yükseklikleri üzerinden değişik gübre uygulamaları için algoritmalar geliştirilerek kullanılabilir. Meralarda toprağı kaplama ile ilgili çalışmalarda NDVI değerleri ile zeminde ölçülen değerler arasında yüksek ilişki (0.71 ve 0.86 ) değerleri belirlenmiştir (Hill et al. 2006; Jiang et al. 2006; Piao et al. 2006). Meralarda karbon stokları hususunda Piao et al. (2006) NDVI bilgileri ile tespitlerde bulunmuşlardır. Meralarda biokütle, yüksek çözünürlüklü NDVI ve RPM verilerinden elde edilen çayır mera ve otlatma sistemlerinin yönetilmesine yardım ile karar verme durumunu değerlendirmek için kullanılabilinir sonucuna varılmıştır. NDVI veritabanı, önceden tespit edilmiş üretim fonksiyonları için ya da daha sonra coğrafik referanslı veri tabanı gibi, sıvı gübre uygulama hızını düzenlemek için kullanılmaktadır (Flynn 2006). Arazi şeklindeki değişkenliğin belirlenmesi, verimlilik, kronik çıplak alanların belirlenmesi, gibi (örneğin gübre, sulama, tarım ilaçları, mera yenileme) etkisinin tahmini ve daha fonksiyonel bir alanda, mera ve otlak yönetimi kararları gibi özel durumlarda yol gösterici olabilmektedir (Hill et al. 1999). Mera çalışmalarında NDVI bilgilerinin kullanılması tarımsal ekonomiye yeni boyut kazandıracağı gibi sonuçların hızlı takibi ve değerlendirilmesi de önem arz etmektedir.

\section{Teşekkür}

Desteklerinden dolayı TÜBITAK (KAMAG Proje No: 106G017) teşekkürlerimizi sunarız.

\section{Kaynaklar}

Altın M., Gökkuş A. ve Koç A., 2011. Çayır ve Mera Yönetimi. Cilt 1. (Genel İlkeler). T.C. Tarım ve Köyişleri Bakanlığı Tarımsal Üretim ve Geliştirme Genel Müdürlüğü. Ankara. Cilt 1. 64-65

Anonim. 2011. Geçit Kuşağı Tarımsal Araştırma Enstitüsü İklim İstasyonu Verileri. (Basılmamış) Eskişehir

Anonim. 2016. Genel Tarım Sayımı www.tuik.gov.tr. DiE. 2001 Erişim tarihi: (03.03.2016)

Aygün C., Kara İ., Sever A. L., Erdoğdu İ., Atalay A. K., Avağ A., Mermer A., Özaydınlı A., Yıldız H., Urla Ö., Aydoğdu M., Ünal E., Aydoğmuş O., Dedeoğlu F., Tuğaç M. G., Torunlar H., Cebel H., Başkan O., Keçeci M ., Depel G. ve Bozkurt M., 2013. Eskişehir İli Mera Topraklarının Bazı Fiziksel Ve Kimyasal Özelliklerinin Belirlenmesi. 3. Ulusal Toprak ve Su Kaynakları Kongresi. 22-24 Ekim 2013. Tokat. s.193-200

Beck P. S. A., Wang T., Skidmore A. K., Liu X. H. and Norut IT A. S., 2008. Displaying remotely sensed vegetation dynamics along natural gradients for ecological studies. International Journal of Remote Sensing. 29(14): 4277-4283

Davis P. H. 1965 (ed 1965-1985). Flora of Turkey and the East Aegean Islands. Vols. 1-9. Edinburgh: Edinburgh University Press

Flynn E.S., 2006. Usıng NDVI as a Pasture Management Tool. Master's Thesis. University of Kentucky p.53. (Unpublished)

Genç L., Turhan H., Demirel K., Çamoğlu G., Aşar B. ve Saçan M., 2008. Bitki Örtme Oranının Spektral Filtreler Yardımıyla Belirlenmesi. Ege Üniv. Ziraat Fak. Dergisi. 45(1):57-63 
Halabuk A., 2011. European Biodiversity Observation Network: Design of a plan for an integrated biodiversity observing system in space and time. D5.2: Report on the use of phenology related measures and indicators for selected sites at varying spatial scales. Ver 1.3.1-27

Hill M J., Donald G.E., Vickery P.J., Moore A.D.and Donnelly J. R., 1999. Combining satellite data with a simulation model to describe spatial variability in pasture growth at a farm scale. Aust. J. Exp. Agric. 39: 285-300

Hill M. J., Held A. A., Leuning R., Coops N. C., Hughes D. and Cleugh H. A., 2006. MODIS spectral signals at a flux tower site: relationships with high-resolution data and $\mathrm{CO}_{2}$ flux and light use efficiency measurements. Remote Sens Environ 103:351-368

Jiang Z., Huete A. R., Chen J., Chen Y., Li J., Yan G. and Zhang X., 2006. Analysis of NDVI and scaled difference vegetation index retrievals of vegetation fraction. Remote Sens Environ 101:366-378

Karayusufoğlu S., Şaylan E L., Çaldağ B., Çaylak O., Semizoğlu E.ve Özkoca Y., Bakanoğulları F., 2011. Uzaktan algılamanın tarımsal meteoroloji'de kullanılmasi: Kırklareli örneği. 5. Atmosfer Bilimleri Sempozyumu 27-29 Nisan 2011. İstanbul. s. 415-422

KoçA. and Gokkus A., 1999. The effect of topografical factors on forage and grazing periods and carrying capacity in Eastern Anatolia Region of Turkey. Proc. XVIII Int. Grassl. Congr. (Ed: J.G. Buchanan-Smith. L.D. Bailey and P. McCaughery). 2: 18-21

Loveland T.R., Reed B.C.; Brown J.F., Ohlen D.O., Zhu J., Yang L. and Merchant J W., 2000. Development of a Global Land Cover Characteristics Database and IGBP DISCover from $1 \mathrm{~km}$ AVHRR Data. International Journal of Remote Sensing.21.13031330

Pettorelli N., Vık J. O., Mysterud A., Gaillard J. M., Tucker C. J. and Stenseth N.C., 2005. Using the satellite-derived NDVI to assess ecological responsesto environmental change. Trends in Ecology and Evolution.20(9):503-510

Piao S., Mohammat A., Fang J., Cai Q. and Feng J., 2006. NDVI-based increase in growth of temperate grasslands and its response to climate changes in China. Global Environ Change 16:340-348

Pitman A.J., 2003. The Evolution of. and Revolution in. Land Surface Schemes Designed for Climate Models. International Journal of Climatology. 23, 479510

Raun W.R., Johnson G.V., Stone M.L., Solie J.B., Lukina E. V. and Thomason W.E., 2001. In-season prediction of potential grain yield in winter wheat using canopy reflectance. Agron. J. 93: 131-178
Raun W.R., Solie J. B., Johnson G. V., Stone M. L., Mullen R. W., Freeman K. W., Thomason W. E. and Lukina E.V., 2002. Improving nitrogen use efficiency in cereal grain production with optical sensing and variable rate application. Agron. J. 94: 815-820

Saroğlu E., 2004. Farklı Çözünürlükteki Uydu Görüntülerinin Geometrik Dönüşümü ve Dönüşüm Sonucunda Elde Edilen Görüntülerin Dış Doğruluğunun Araştırılması. Yüksek Lisans Tezi. ITÜ Fen Bilimleri Enstitüsü. (Basılmamış) İstanbul

Sertel E., 2008. Remote Sensing and Regional Climate Modeling of the İmpacts of land Cover Changes on the Climate of the Marmara Region of Turkey, Doktora Tezi ITU Fen Bilimleri Enstitüsü, (Basılmamış) İstanbul

Sertel E. ve Örmeci C, 2009. Uzaktan Algılama Verilerinin İklim Biliminde Kullanım Olanakları, TMMOB Harita ve Kadastro Mühendisleri Odası 12. Türkiye Harita Bilimsel ve Teknik Kurultayı 1115 Mayıs 2009, Ankara

Sertel E. ve Örmeci C., 2009. Bölgesel İklim Modellemede Kullanılan Arazi Örtüsü Verilerinin Doğruluğunun Araştırılması, ITU Dergisi 8 (3): 29-38

Sellers P.J., Los O. L., Tucker C. J., Justice C.O., Dazlich D. A., Collatz G.J. and Randall D. A., 1996. A Revised Land Surface Parameterization (Sib2) for Atmospheric Gcms. Part II: The Generation of Global Fields of Terrestrial Biophysical Parameters From Satellite Data. Journal of Climate, sayı: 9, sayfa: 706737

Skole D.L. and Tucker C.J., 1993. Tropical deforestation and habitat fragmentation in the Amazon: satellite data from 1978 to 1988. Science 260, 190-1910

Teal R.K., Tubana B., Girma K.; Freeman K.W., Arnall D.B., Walsh O. and Raun W.R., 2006. Inseason prediction of corn grain yield potential using normalized difference vegetation index. Agron. J. 98: 1488-1494

Terzioğlu Ö. ve Yalvaç N. 2004. Van yöresi doğal meralarında otlatmaya başlama zamanı kuru ot verimi ve botanik kompozisyonun belirlenmesi üzerine bir araştırma. YYU. Ziraat Fakültesi Tarım Bil. Derg., (J. Agric. Sci.) 14(1): 23-26

Tubana B.S., Arnall D.B., Walsh O., Chung B., Solie J.B., Girma K. and Raun W.R., 2008. Adjusting midseason nitrogen rate using a sensor-based optimization algorithm toincrease use efficiency in corn. J. Plant Nutr. 31: 1393-1419

Yin X., Mc Clure A.and Tyler D., 2010. Relationships of plant height and canopy NDVI with nitrogen nutrition and yields of corn. 19 ${ }^{\text {th }}$ World Congress of Soil Science. Soil Solutions for a Changing World 1 - 5 August 2010. Brisbane. Australia 